\title{
Experimental and 3D-ANN based Analysis and Prediction of Cutting Forces, Tool Vibration and Tool Wear in Boring of Ti-6Al-4V Alloy
}

\author{
P. B. G. S. N. Murthy ${ }^{*}$, Ch. Srinivasa Rao ${ }^{2}$ and K. Venkata Rao ${ }^{1}$ \\ ${ }^{1}$ Department of Mechanical Engineering, Vignan's Foundation for Science, \\ Technology and Research, Vadlamudi, India. \\ *Email: pbgsnmurthy@gmail.com \\ Phone: +919440062101 \\ ${ }^{2}$ Department of Mechanical Engineering, Andhra University, Vishakaptnam, India.
}

\begin{abstract}
In this work, accurate 3D finite element models were developed to study and predict machining characteristics like tool vibration, tool wear, surface roughness, cutting force and thrust forces in the boring of Ti-6Al-4V alloy. Experiments were conducted on the proposed metal using carbide inserts at three levels of spindle speeds, depth of cuts and feed rates and experimental results were collected. Numerical simulation was carried out using Deform 3D software. Johnson-cook material model was also used in simulation to predict the machining characteristics. A Usui's wear model was taken in simulation to calculate tool wear at different working conditions. Experimental data of the five machining characteristics were analysed using analysis of variance to identify the most significant parameters. Cutting speed, depth of cut and feed rate were found to be the most significant parameters. Simulated results of the machining characteristics were compared with the experimental data and found in a good agreement between them. An Artificial neural network (ANN) model was also developed and trained with the experimental data to validate the results. FEM simulation models provide relevant machining information without conducting experimentation for any metal.
\end{abstract}

Keywords: Tool wear; tool vibration; finite element model; cutting forces; surface roughness.

\section{INTRODUCTION}

Ti-6Al-4V is one type of titanium alloys having good properties like toughness, corrosion resistance, and strength to weight ratio. Due to these properties, it is widely used in marine, aerospace and biomedical applications [1-2]. Dry machining of titanium alloys is a difficult operation due to high co-efficient of friction at tool chip interface, high stress at the shear zone, high temperature and also the presence of chip ignition [3]. Milling, Drilling, and boring are considered as vibration induced operations because of the length of tool/cutter from the tool post. In boring operation, due to the length of the tool holder, the tools have the least rigidity and are subjected to cutting forces and vibration while machining. The tool vibration is considered as a critical parameter that affects the tool life, surface finish and tooling cost [4].

Vibration can be said to be a cyclic movement about a mean position. Inman [5] stated that the vibration has a great impact on the surrounding environment. Figure 1 represents a forced vibration system having one degree of freedom. If a system vibrates 
due to the presence of force, that is called forced vibration. Vibrations in IC engines, machine tools and air compressors are the examples for the forced vibrations.

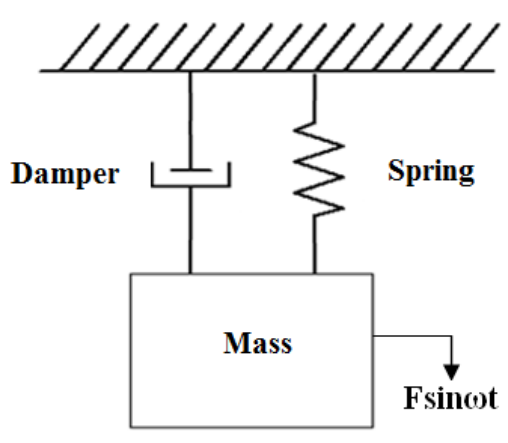

Figure 1. Single degree of freedom forced vibration system

In the boring process, static deflection of the boring bar (tool holder) causes errors in the functional dimensions. Hence, it is required to model the vibration of the tool holder to check the integrity of tolerance [6]. As the tool holder is similar to the cantilever beam, which is subjected to a point load at its free end. Static analysis of tool holder was performed using a cantilever beam model to estimate maximum deflection of the tool during the machining. In the boring process, the boring bar is rigidly held in the tool post of the machine tool, and it acts as a cantilever beam. The following equation is used to calculate the deflection of the boring bar [7]:

$\delta=\frac{\mathrm{F}_{\mathrm{r}} \mathrm{L}^{3}}{3 . \mathrm{E} . \mathrm{I}}$

where $F_{r}$ is the radial force, $L$ is the length of the boring bar, $E$ is the modulus of elasticity, $I$ is area moment of inertia and $D$ is the diameter of a bar.

Moment of inertia, $\mathrm{I}=\frac{\pi \mathrm{D}^{4}}{64}$

Miguélez et al. [8] investigated the dynamic behaviour of a boring tool holder in machining of different steels and cast iron. Accelerometers were used to measure the vibrations in both the directions of cutting speed and the cutting depth. In one direction, it was found that the vibrations were influenced by the first resonance frequency. Influence of tool vibration on the surface finish in turning was investigated by Wang et al. [9]. They found turning marks on the workpiece and spatial errors in radial direction measurement.

The titanium alloys are introduced in making of aeronautical components having a large area with less thickness. Machining of titanium alloys involves high cutting forces that results in high vibrations and damages the machine as well as cutters. Mechanistic models are used to develop cutting force models for prediction of cutting forces in machining of hard metals like Ti-6Al-4V alloy. This model was also used to investigate the effect of ploughing on cutting forces [10]. Mehmet et al. [11] developed a methodology to predict cutting forces using force distribution during machining of 7075T651 aluminium. The force distribution is characterised based on tool geometry and cutting parameters. The proposed methodology helped in the improvement of machining accuracy. Hamed et al. [12] investigated the effect of cutting conditions on cutting forces 
and surface roughness in machining of Ti-6Al-4V alloy. They conducted experiments on the Ti-6Al-4V alloy at different levels of speed, feed rate and axial depth of cut and experimental data of surface roughness and cutting force were measured. They concluded that the cutting speed is an influencing factor that affects the surface roughness and cutting forces.

Boring of Ti-6Al-4V is indeed a challenging task due to poor machinability, high cutting forces, the tendency of chip ignition, tool vibration and tool wear resulting in poor surface finish. Therefore, researchers have been exercising the simulation of machining using three-dimensional finite element methods (FEM) to study the effect of process parameters on machining characteristics. 3D FEM machining models visualise the machining process and also help to analyse the machining characteristics such as tool vibration, cutting forces, tool wear, shear stress and temperature [13]. Ducobu et al. [14] have carried out a numerical simulation to study adiabatic shear band and mechanics of chip formation on Ti-6Al-4V alloy. Material models like Johnson-cook, hyperbolic tangent and Arbitrary Lagrangian-Eulerian were used in the numerical simulation. Filice et al. [15] used the DEFORM 2D and DEFORM 3D FEM software to investigate the distribution of temperature in machining of AISI 1045 steel. The simulation results were compared with experimental results, and then it was concluded that the DEFORM 3D accurately predicts the temperature distribution.

Arulkirubakaran et al. [16] carried out a numerical simulation using DEFORM 3D software along with the Lagrangian formulation to investigate the effect of texture on the tool face on machining characteristics in machining of Ti-6Al-4V alloy. Johnsoncook material model was proposed for thermo-mechanical analysis to predict tool wear, cutting forces, temperature distribution and chip formation. Experiments were also carried out on the same material to validate the simulation results and found good agreement between experimental results and simulation results. Mohammad et al. [17] stated that experimental investigation of tool wear is a costlier approach, and hence 3D FEM models are developed to predict tool wear in machining of any metal. They developed 3D FEM models using Usui wear model to predict tool wear in machining of Inconel 625 using PVD-TiAlN tool. Predictive values of the FEM models are compared with experimental values, and a good agreement was found between them. Researchers are also using an artificial neural network (ANN), support vector machine, and response surface method to predict machining characteristics and optimise process parameters. The ANN is intelligence based soft computing technique that predicts the machining characteristics with higher accuracy [18-20].

Based on the above literature, it was observed that the 3D FEM models are very much useful to study the machining characteristics especially for machining of hard metals like titanium alloys. Therefore, 3D FEM models have been developed in the present study to investigate machining characteristics such as cutting forces, tool wear and vibration of the tool in machining of Ti-6Al-4V alloy. Experiments (boring) were conducted on Ti-6Al-4V alloy and results were validated with simulation results. In additions, ANN models were developed, trained with experimental data and predicted the machining characteristics. Results of the three approaches were compared. Furthermore, the effect of process parameters on the machining characteristics was also studied.

\section{EXPERIMENTAL SETUP AND FE MODELING}

In the present study, Ti-6Al-4V titanium alloy was taken to study its machining characteristics. The round workpiece with a diameter of $80 \mathrm{~mm}$ and length of $100 \mathrm{~mm}$ 
length and the inner diameter of $60 \mathrm{~mm}$ was bored with uncoated DNMA 432 Sandvik type tungsten carbide tool insert. Design of experiments (DOE) was prepared with three levels of spindle speed, depth of cut and feed as presented in Table 1. In this study, cutting speed in terms of $\mathrm{m} / \mathrm{min}$ is not taken because the bore diameter is increased in every pass, the reason why, the spindle speed was taken in the analysis/study. Tool parameters are taken as rake angle of $-5^{\circ}$, the clearance angle of $8^{\circ}, 0.8 \mathrm{~mm}$ of nose radius $4.7625 \mathrm{~mm}$ of cutting-edge length and $6.477 \mathrm{~mm}$ of rake face length $(\mathrm{mm})$. Detailed experimental plan is given below:

i. As per the design of experiments, each experiment was started with a new tool insert on the automated turning machine tool.

ii. As shown in Figure 2, a Poly Tech 100-V type laser Doppler vibrometer (LDV) was placed in front of the machine and directed laser beam on tool holder to measure its vibration.

iii. A Kistler 9272 four-component type dynamometer with a multichannel analyser was used to measure cutting forces in cutting direction and in the direction perpendicular to cutting direction.

iv. After machining, surface roughness and tool wear were measured using SJ-310 type Talysurf and machine vision system respectively.

v. Experimental results of tool vibration $(Y)$, cutting force $\left(F_{C}\right)$, thrust force $\left(F_{T}\right)$, flank wear $\left(V_{B}\right)$ and surface roughness $\left(R_{a}\right)$ were presented in Table 2.

Table 1. Machining parameters with three levels

\begin{tabular}{lcccc}
\hline Factor & Unit & Level 1 & Level 2 & Level 3 \\
\hline Spindle speed (S) & RPM & 800 & 1000 & 1200 \\
Depth of cut (D) & $\mathrm{mm}$ & 0.2 & 0.3 & 0.4 \\
Feed (F) & $\mathrm{mm} / \mathrm{rev}$ & 0.1 & 0.2 & 0.3 \\
\hline
\end{tabular}

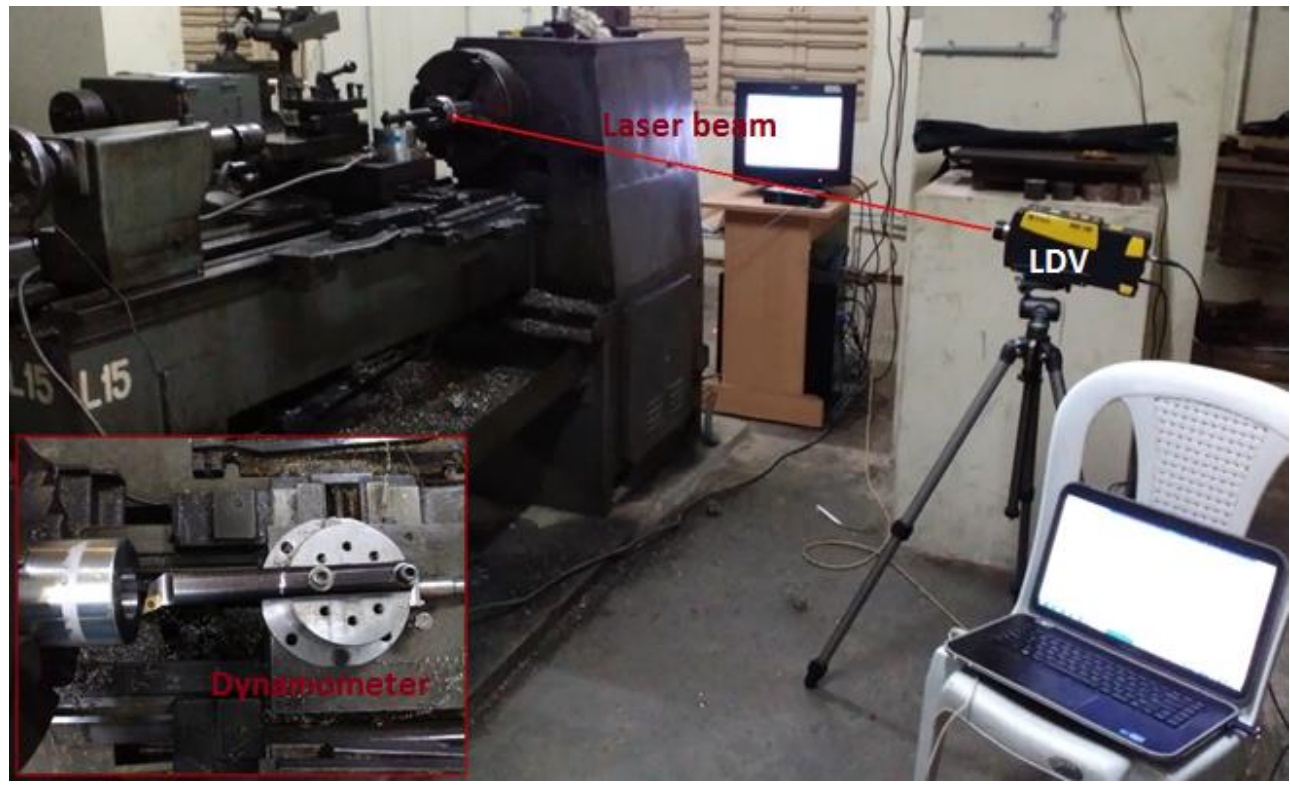

Figure 2. Experimental setup and dynamometer (inset) 
Table 2. Experimental and simulated results of machining characteristics

\begin{tabular}{|c|c|c|c|c|c|c|c|c|c|c|c|c|}
\hline \multirow[t]{2}{*}{ Exp. } & \multirow{2}{*}{$\begin{array}{c}\mathrm{S} \\
(\mathrm{rpm})\end{array}$} & \multirow{2}{*}{$\begin{array}{c}\mathrm{D} \\
(\mathrm{mm})\end{array}$} & \multirow{2}{*}{$\begin{array}{c}\mathrm{F} \\
(\mathrm{mm} / \mathrm{rev})\end{array}$} & \multicolumn{2}{|c|}{$\mathrm{Y}(\mathrm{mm})$} & \multicolumn{2}{|c|}{$\mathrm{F}_{\mathrm{C}}(\mathrm{N})$} & \multicolumn{2}{|c|}{$\mathrm{F}_{\mathrm{T}}(\mathrm{N})$} & \multicolumn{2}{|c|}{$\mathrm{V}_{\mathrm{B}}(\mathrm{mm})$} & \multirow{2}{*}{$\begin{array}{c}\mathrm{R}_{\mathrm{a}} \\
(\mu \mathrm{m})\end{array}$} \\
\hline & & & & Exp. & Sim. & Exp. & Sim. & Exp. & Sim. & Exp. & Sim. & \\
\hline 1 & 800 & 0.2 & 0.1 & 0.0335 & 0.0325 & 675 & 643 & 209 & 202 & 0.064 & 0.048 & 1.912 \\
\hline 2 & 800 & 0.3 & 0.1 & 0.0357 & 0.0442 & 706 & 689 & 227 & 211 & 0.069 & 0.063 & 2.010 \\
\hline 3 & 800 & 0.4 & 0.1 & 0.0385 & 0.0440 & 741 & 725 & 244 & 236 & 0.078 & 0.072 & 2.238 \\
\hline 4 & 800 & 0.2 & 0.2 & 0.0510 & 0.0482 & 825 & 808 & 267 & 253 & 0.072 & 0.094 & 2.312 \\
\hline 5 & 800 & 0.3 & 0.2 & 0.0410 & $0 / 0357$ & 841 & 825 & 283 & 287 & 0.083 & 0.095 & 2.414 \\
\hline 6 & 800 & 0.4 & 0.2 & 0.0427 & $0 / 0512$ & 914 & 895 & 302 & 294 & 0.092 & & 2.489 \\
\hline 7 & 800 & 0.2 & 0.3 & 0.0522 & $0 / 0527$ & 985 & 962 & 325 & 313 & 0.088 & & 2.712 \\
\hline 8 & 800 & 0.3 & 0.3 & 0.0540 & & 1043 & 1011 & 347 & 320 & 0.097 & 100 & 2.790 \\
\hline 9 & 800 & 0.4 & 0.3 & 0.0559 & $0 / 05$ & 1102 & 1094 & 354 & 322 & 0.121 & 0.130 & 2.915 \\
\hline 10 & 1000 & 0.2 & 0.1 & 0.0562 & 0.0545 & 698 & 660 & 258 & 234 & 0.118 & 0.115 & 2.015 \\
\hline 11 & 1000 & 0.3 & 0.1 & 0,0579 & 0.0550 & 728 & 703 & 285 & 253 & 0.130 & 0.125 & 2.104 \\
\hline 12 & 1000 & 0.4 & 0.1 & 0.0592 & 0.0612 & 769 & 747 & 286 & 274 & 0.145 & 0.143 & 2.290 \\
\hline 13 & 1000 & 0.2 & 0.2 & 0.0602 & 0.0587 & 843 & 811 & 304 & 298 & 0.122 & 0.133 & 2.491 \\
\hline 14 & 1000 & 0.3 & 0.2 & 0.0657 & 0.0667 & 870 & 823 & 317 & 313 & 0.148 & 0.146 & 2.563 \\
\hline 15 & 1000 & 0.4 & 0.2 & 0.0665 & 0.0707 & 989 & 961 & 343 & 329 & 0.157 & 0.164 & 2.715 \\
\hline 16 & 1000 & 0.2 & 0.3 & 0.0762 & 0.0717 & 1015 & 982 & 352 & 329 & 0.145 & 0.194 & 3.102 \\
\hline 17 & 1000 & 0.3 & 0.3 & 0.0775 & 0.0752 & 1062 & 1037 & 362 & 361 & 0.150 & 0.182 & 3.435 \\
\hline 18 & 1000 & 0.4 & 0.3 & 0.0785 & 0.0792 & 1109 & 1019 & 389 & 376 & 0.165 & 0.195 & 3.562 \\
\hline 19 & 1200 & 0.2 & 0.1 & 0.0802 & 0.0830 & 739 & 692 & 270 & 252 & 0.177 & 0.157 & 2.123 \\
\hline 20 & 1200 & 0.3 & 0.1 & 0.0892 & 0.0810 & 783 & 758 & 280 & 267 & 0.163 & 0.184 & 2.281 \\
\hline 21 & 1200 & 0.4 & 0.1 & 0.0960 & 0.0945 & 814 & 806 & 295 & 272 & 0.195 & 0.114 & 2.312 \\
\hline 22 & 1200 & 0.2 & 0.2 & 0.0990 & 0.1020 & 895 & 848 & 315 & 298 & 0.189 & 0.205 & 2.812 \\
\hline 23 & 1200 & 0.3 & 0.2 & 0.1002 & 0.1012 & 951 & 914 & 329 & 305 & 0.204 & 0.226 & 2.913 \\
\hline 24 & 1200 & 0.4 & 0.2 & 0.1040 & 0.1032 & 1026 & 1004 & 330 & 312 & 0.242 & 0.225 & 2.989 \\
\hline 25 & 1200 & 0.2 & 0.3 & 0.1062 & 0.1050 & 1045 & 1023 & 341 & 323 & 0.281 & 0.274 & 3.523 \\
\hline 26 & 1200 & 0.3 & 0.3 & 0.1070 & 0.1080 & 1107 & 1080 & 367 & 348 & 0.312 & 0.348 & 3.612 \\
\hline 27 & 1200 & 0.4 & 0.3 & 0.1095 & 0.1072 & 1198 & 1146 & 382 & 370 & 0.335 & 0.324 & 3.791 \\
\hline
\end{tabular}

\section{D FE MODELING AND SIMULATION}

In the present work, DEFORM 3D v6.1 with Lagrangian formulation was used to simulate the boring process. During the simulation, DNMA 432 Sandvik type cemented carbide tool insert selected from the tools library and a tool holder is defined with a rake angle of $-5^{\circ}$, the clearance angle of $-10^{\circ}$ was used. Properties of tool and workpiece materials were selected from the materials library provided in the software. The tool inserts and workpieces were meshed with 25,000 and 65,000 elements respectively and an adoptive remeshing scheme is implemented for simulation (Figure 3(a)). In the simulation, the tool is assumed to be rigid and work piece is assumed to be plastic. The Johnson-Cook material model is commonly used in the metal cutting simulation due to its ability to predict machining characteristics accurately. Plastic flow stress during the machining is formulated in terms of strain hardening, strain rate and thermal softening as shown in the Eq. (3) [21].

$\sigma_{\mathrm{f}}=\left[\mathrm{A}+\mathrm{B}(\varepsilon)^{\mathrm{n}}\right]\left[1+\mathrm{C} \ln \left(\frac{\varepsilon^{\mathrm{o}}}{\varepsilon_{0}^{\mathrm{o}}}\right)\right]\left[1-\left(\frac{\mathrm{T}-\mathrm{T}_{\text {room }}}{\mathrm{T}_{\text {melt }} \mathrm{T}_{\text {room }}}\right)^{\mathrm{m}}\right]$

where $\sigma_{\mathrm{f}}$ is equivalent flow stress, $\varepsilon$ is an equivalent plastic strain and $\varepsilon^{\mathrm{o}} / \varepsilon_{0}^{0}$ is the reference strain rate. $\mathrm{A}, \mathrm{B}, \mathrm{C}, \mathrm{n}$ and $\mathrm{m}$ are the material constants, $\mathrm{T}_{\text {room }}$ is room temperature of $20^{\circ}$ and $\mathrm{T}_{\text {melt }}$ is the melting point of the metal. Material properties and the Johnson-Cook parameters are inbuilt in software. A constant shear model was adapted to model friction at tool-workpiece interface as shown in the Eq. (4). 
$\tau=\mathrm{mk}$

where $k$ is the shear flow stress of workpiece at tool-chip interface and $m$ is the constant shear friction factor which was taken as 0.6 [22].

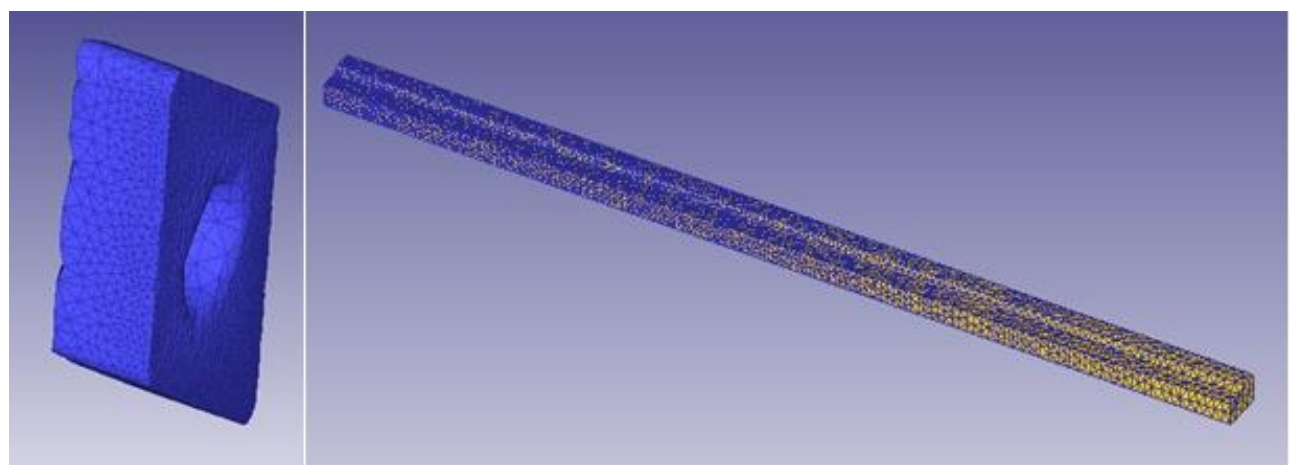

(a)

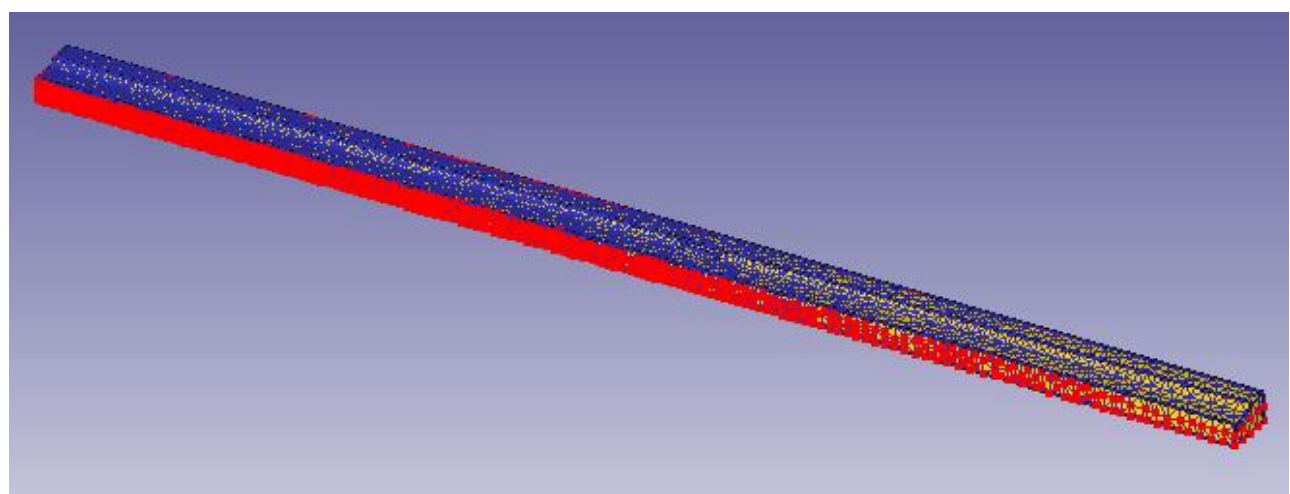

(b)

Figure 3. (a) Meshed tool insert and workpiece and; (b) workpiece boundary conditions.

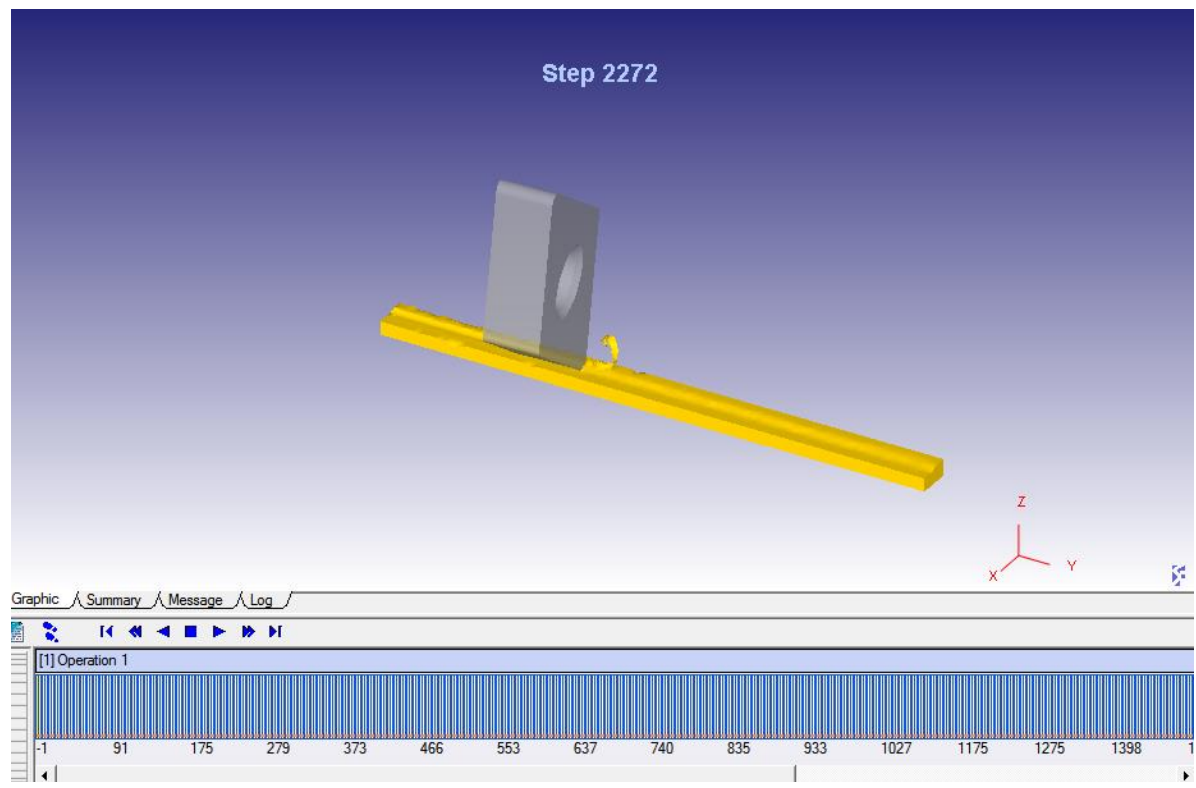

Figure 4. Simulation of the boring process. 
In Figure 3(b), the workpiece is fully constrained at lateral sides and bottom. During the simulation, a coupled thermo-mechanical analysis along with Johnson-cook material model was used to predict cutting forces, displacement of cutter and tool wear. Figure 4 shows the simulation of tool movement and formation of a chip. In the present work, the tool wear rate was modelled using Usui's wear rate model in Eq. (5) to estimate the wear rate [23].

$\frac{\mathrm{dw}}{\mathrm{dt}}=\mathrm{A} \sigma_{\mathrm{n}} \mathrm{V}_{\mathrm{s}} \mathrm{e}^{(-\mathrm{B} / \mathrm{T})}$

where $A$ and $B$ are yield strength and hardening modulus, $V_{s}$ is sliding velocity and $T$ is temperature.

\section{RESULTS AND DISCUSSION}

Experimental and simulated data of cutting force, thrust force, cutter vibration amplitude and flank wear for 27 working condition are presented in Table 2. In addition to that, experimental data of surface roughness is also incorporated in the same table. There is good agreement between experimental results and simulated results. In the analysis of experimental data, analysis of variance (ANOVA) was carried out at $95 \%$ of confidence level. The individual process parameters which are having a p-value less than 0.05 are identified to be significant [24]. ANOVA for the five responses was given in Table 3.

Table 3 Analysis of variance for experimental data of machining characteristics

\begin{tabular}{cccccc}
\hline Factor & \multicolumn{3}{c}{$\mathrm{p}$-value } \\
& $\mathrm{Y}$ & $\mathrm{F}_{\mathrm{C}}$ & $\mathrm{F}_{\mathrm{T}}$ & $\mathrm{V}_{\mathrm{B}}$ & $\mathrm{Ra}$ \\
\hline $\mathrm{SS}$ & 0.015 & 0.001 & 0.001 & 0.000 & 0.001 \\
$\mathrm{D}$ & 0.057 & 0.003 & 0.009 & 0.063 & 0.072 \\
$\mathrm{~F}$ & 0.000 & 0.002 & 0.001 & 0.002 & 0.001 \\
\hline
\end{tabular}

\section{Cutting Force and Thrust Force}

Based on the experimental, simulated and ANOVA results shown in Table 3, speed, depth of cut and feed rate were found to be the most influential parameter on cutting force. Interaction effect of process parameters on the cutting force and thrust force is presented in Figure 5 and Figure 6 respectively. As per Figure 5 (a) and (b), the cutting force increased with the increase of the feed rate, depth of cut and cutting speed. But the effect of the spindle speed is less on the cutting force when compared with the remaining parameters. At high cutting speeds, the workpiece metal is subjected to thermal softening. Hence the spindle speed has less significance on the cutting forces as well as thrust forces [25]. Whereas in Figure 5(c), the effect of the depth of cut is less when compared with the feed rate. The cutting force was found to be increased as feed was increased for all the levels of depth of cuts. At high feed rates and depth of cuts, more energy is required for plastic deformation of metal. Consequently there is a rise in temperature and friction in the cutting zone that results in tool wear. Therefore, the cutting forces were increased [19].

Figure 6 (a) to (c) show the interaction effect of the process parameters on the thrust force. The thrust force was also increased as the three parameters have been increased. But, the spindle speed has a mixed effect on the thrust force at all the levels of 
depth of cut. The thrust force was increased as spindle speed was increased up to around $1100 \mathrm{rpm}$ and then the thrust force reduced from 1100 to $1200 \mathrm{rpm}$. Figures 7 and 11 shows the cutting force and thrust forces for the first experiment at $800 \mathrm{rpm}$ of spindle speed, $0.2 \mathrm{~mm}$ depth of cut and $0.1 \mathrm{~mm} / \mathrm{rev}$ of feed rate respectively. The simulation figures also represent variation in the forces concerning time and length of cutting.
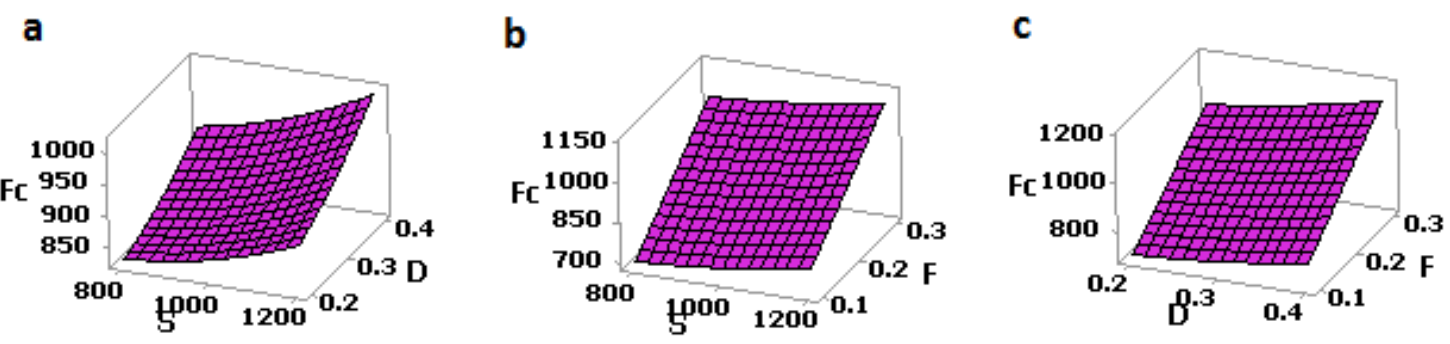

Figure 5. Interaction effect of process parameters on $\mathrm{F}_{\mathrm{C}}$

a

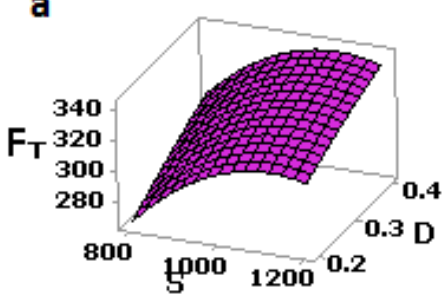

b

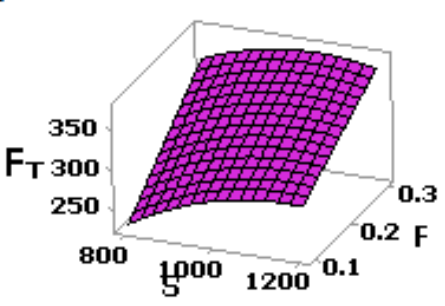

C

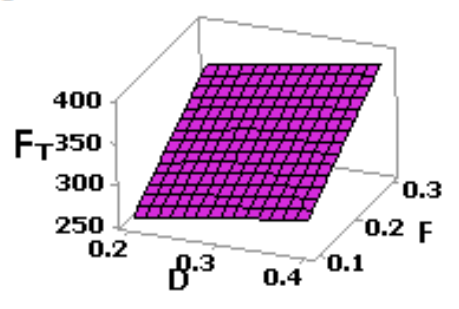

Figure 6. Interaction of the effect of process parameters on $\mathrm{F}_{\mathrm{T}}$.

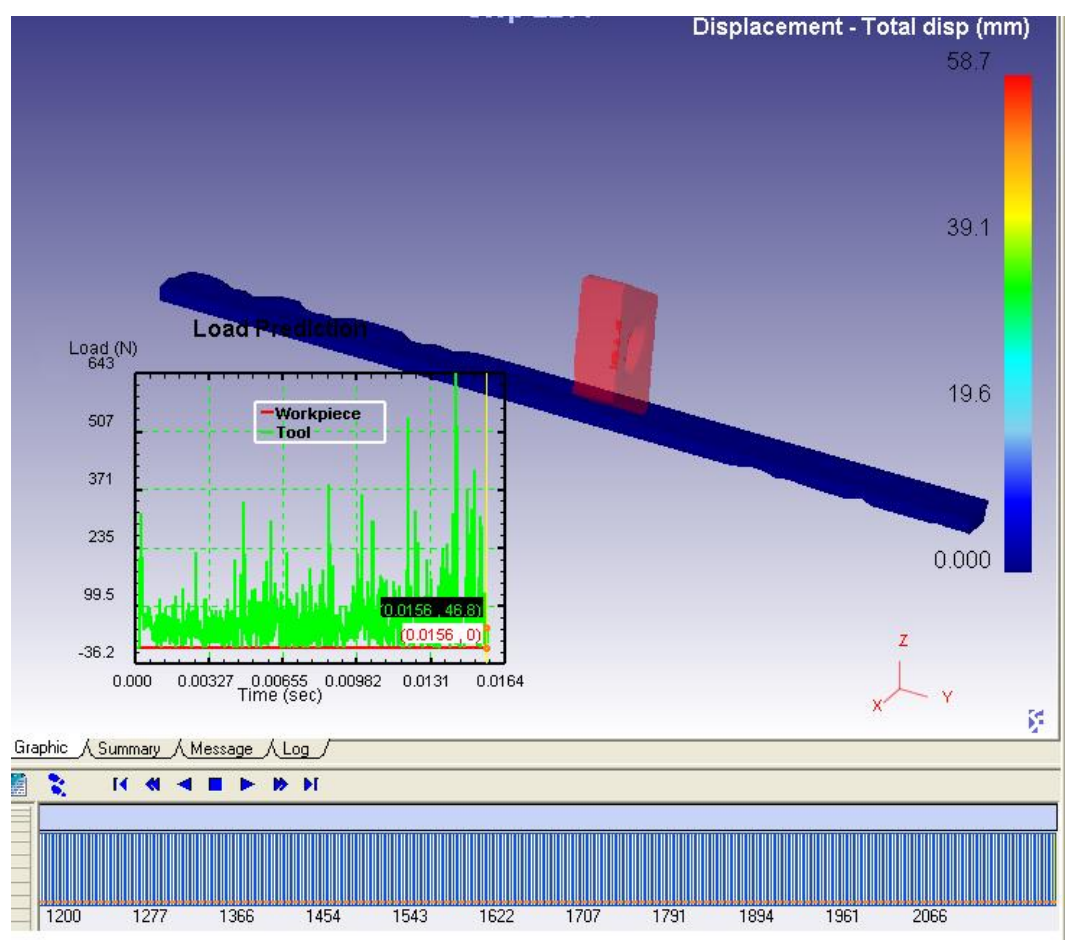

Figure 7. Simulated cutting force. 


\section{Flank Wear}

Wear on the tool flank was measured using a machine vision system and presented in Table 2. Based on the experimental results, simulated results and ANOVA of flank wear, spindle speed and feed rate were found to be the most influential parameters on flank wear in the boring of Ti-6Al-4V alloy. Interaction effect of process parameters on the flank wear is presented in Figure 8. Size of the flank wear was increased by the increment of spindle speed and feed rate. Due to lower friction coefficient, anti-adhesion and hot hardness under $1000{ }^{\circ} \mathrm{C}$, the tungsten carbide tools become suitable to use high cutting speeds in machining of hard metals [14].

In this study, Usui's tool wear model was used to investigate the propagation of flank wear at different working conditions. Figure 9 shows the progress of the flank wear rate for the first experiment at $800 \mathrm{rpm}$ of spindle speed, $0.2 \mathrm{~mm}$ depth of cut and 0.1 $\mathrm{mm} / \mathrm{rev}$ of feed rate. During the machining, the energy of plastics deformation is converted in frictional heat at the tool-chip interface and increased as the spindle speed, and feed rate increased. Due to the poor thermal conductivity of the Ti-6Al-4V, temperature raises rapidly at tool-workpiece interface and therefore faster wear takes place on the tool [26-27].

a

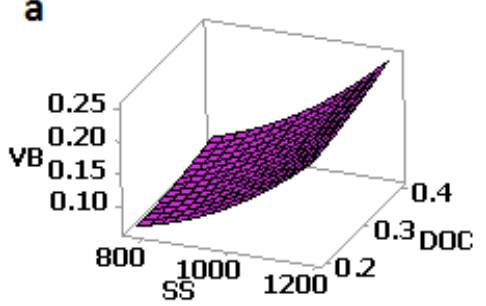

b

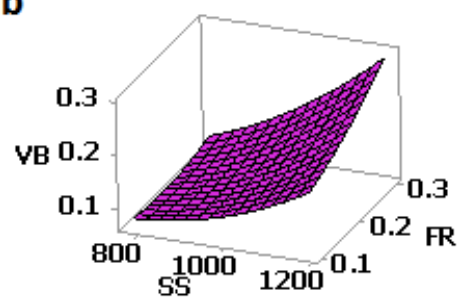

C

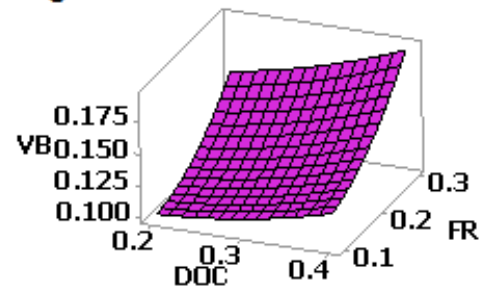

Figure 8. Interaction effect of process parameters on $\mathrm{V}_{\mathrm{B}}$.

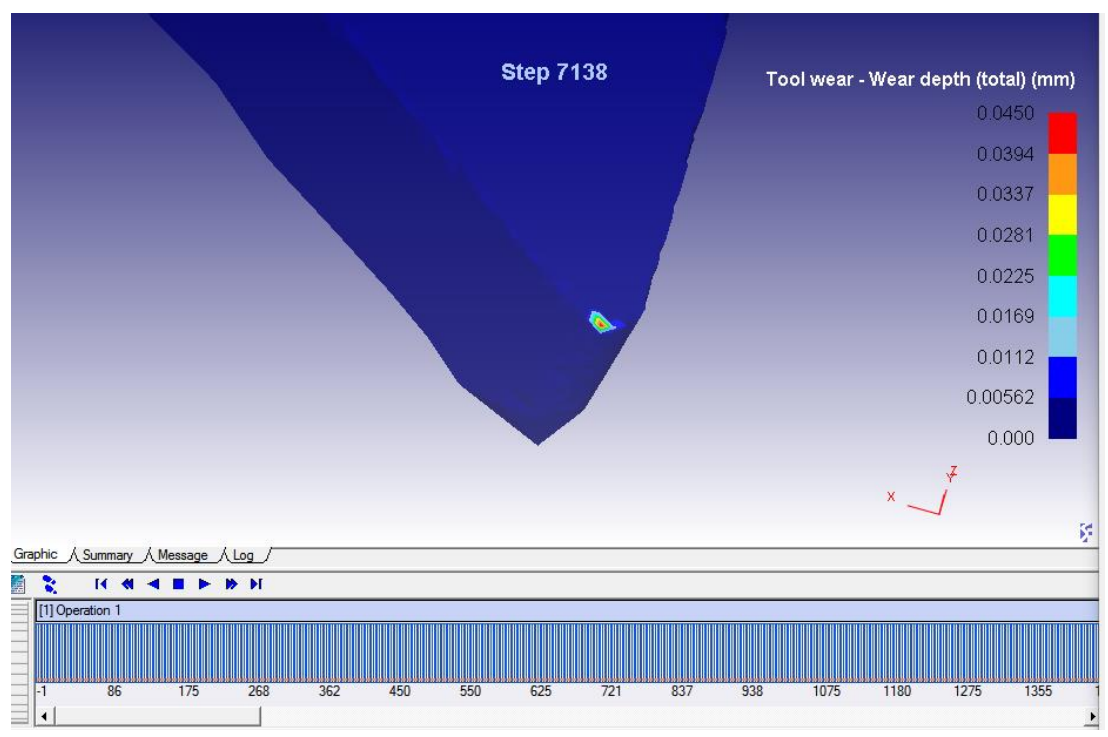

Figure 9. Simulated flank wear. 


\section{Amplitude of Cutter Vibration}

Based on the experimental results, simulated results and ANOVA (Table 3), the two process parameters have a significant effect on the amplitude of cutter vibration. Interaction effect of process parameters on the cutter vibration is shown in Figure 10, where the spindle speed and feed rate have more effect on the cutter vibration. Figure 11 shows the vibration of cutter working at $800 \mathrm{rpm}$ of spindle speed, $0.2 \mathrm{~mm}$ depth of cut and $0.1 \mathrm{~mm} / \mathrm{rev}$ of feed rate. During the machining, the level of the cutter vibration increases while tool wear progresses.

At the starting of the machining, the tool is sharp, and wear takes place on the tool as the cutting progresses. Wear on the tool makes the machining unstable and then affects the machining dynamics, which results in variation in cutting forces and tool vibrations. Therefore, the amplitude of cutter vibration is less at starting and increases as the tool wear increase [28]. In addition to that, elastic recovery during the machining results in friction induced vibrations [29].
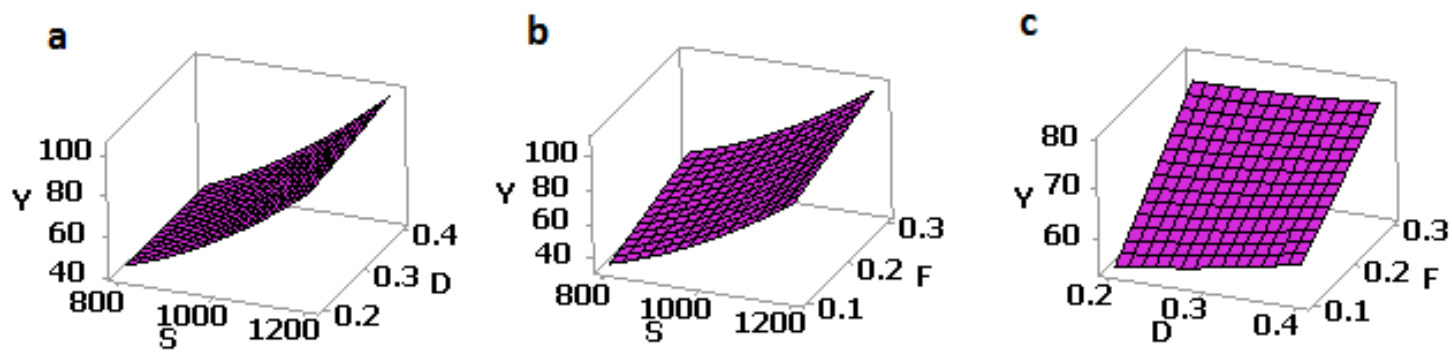

Figure 10. Interaction effect of process parameters on Y.

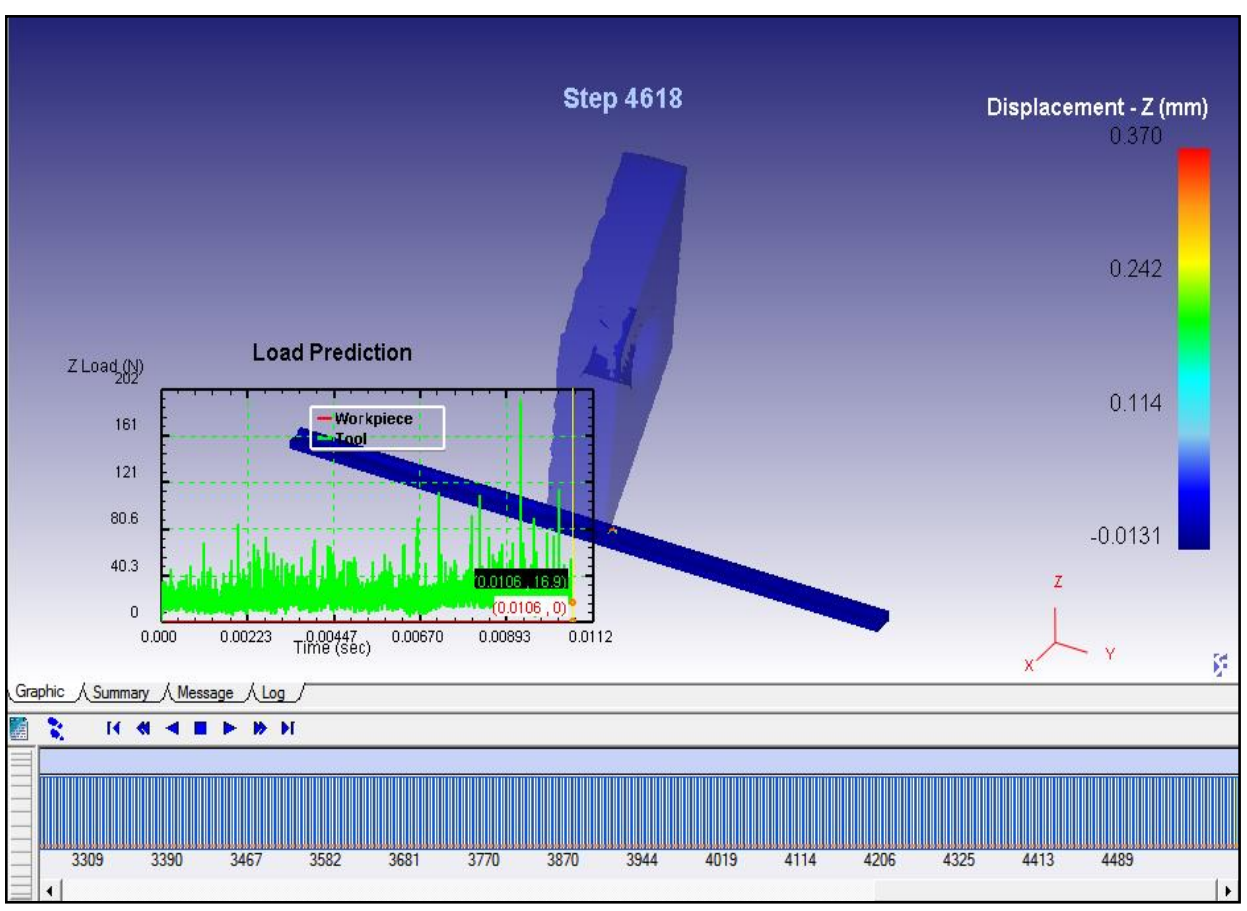

Figure 11. Simulated amplitude of cutter vibration and thrust force 


\section{Surface Roughness}

Based on the experimental results and ANOVA in Table 3, two process parameters have a significant effect on the surface roughness. Interaction effect of process parameters on the roughness is shown in Figure 12, where the spindle speed and feed rate have the most effect on the surface roughness.
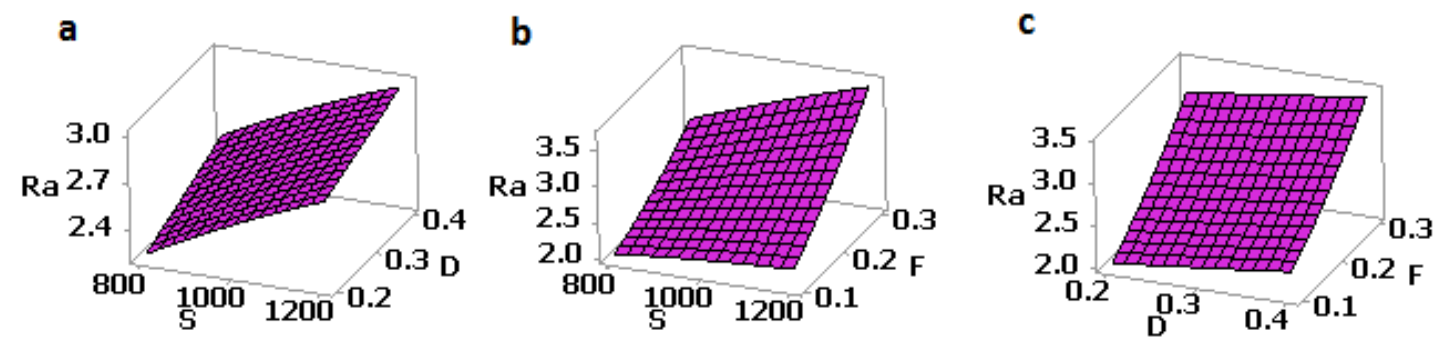

Figure 12. Interaction effect of process parameters on Ra

\section{ARTIFICIAL NEURAL NETWORKS}

Artificial neural network (ANN) is one of the advanced methodologies used in manufacturing to predict machining characteristics and optimise the process parameters. The neural network was developed from the biological neural networks [24]. In the present work, the network is constructed with three layers such as input layer, an output layer and hidden layers between input and output layers. As shown in Figure 13, each layer has neurons or nodes, and there are connections between the neurons to transfer the information from one layer to the next layer.

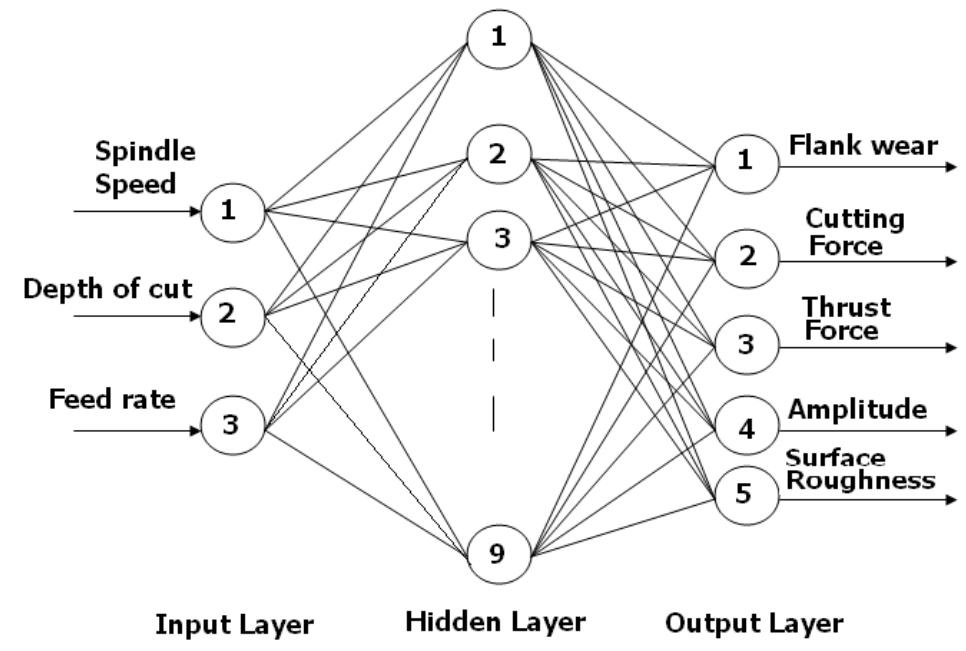

Figure 14. Feedforward 3-9-5 neural network.

Twenty-three samples of experimental data were used to train the network among which six samples were used for validation, and four samples of experimental data were used to test the data. As shown in Figure 15, the network was trained using a feed forward back propagation algorithm with a learning rate of 0.6 and momentum of 0.8 . During the 
training, target error was set to 0.01 and training was stopped when the average training error was less than 0.01. After training, the network was used to test the experimental data. Experimental results and responses predicted by simulation and neural network are presented in Table 4 (a) and (b). The error between the experimental results and ANN predicted results were estimated and presented in Table 4 (a) and (b). There is a good agreement between predicted and experimental results of the three responses.

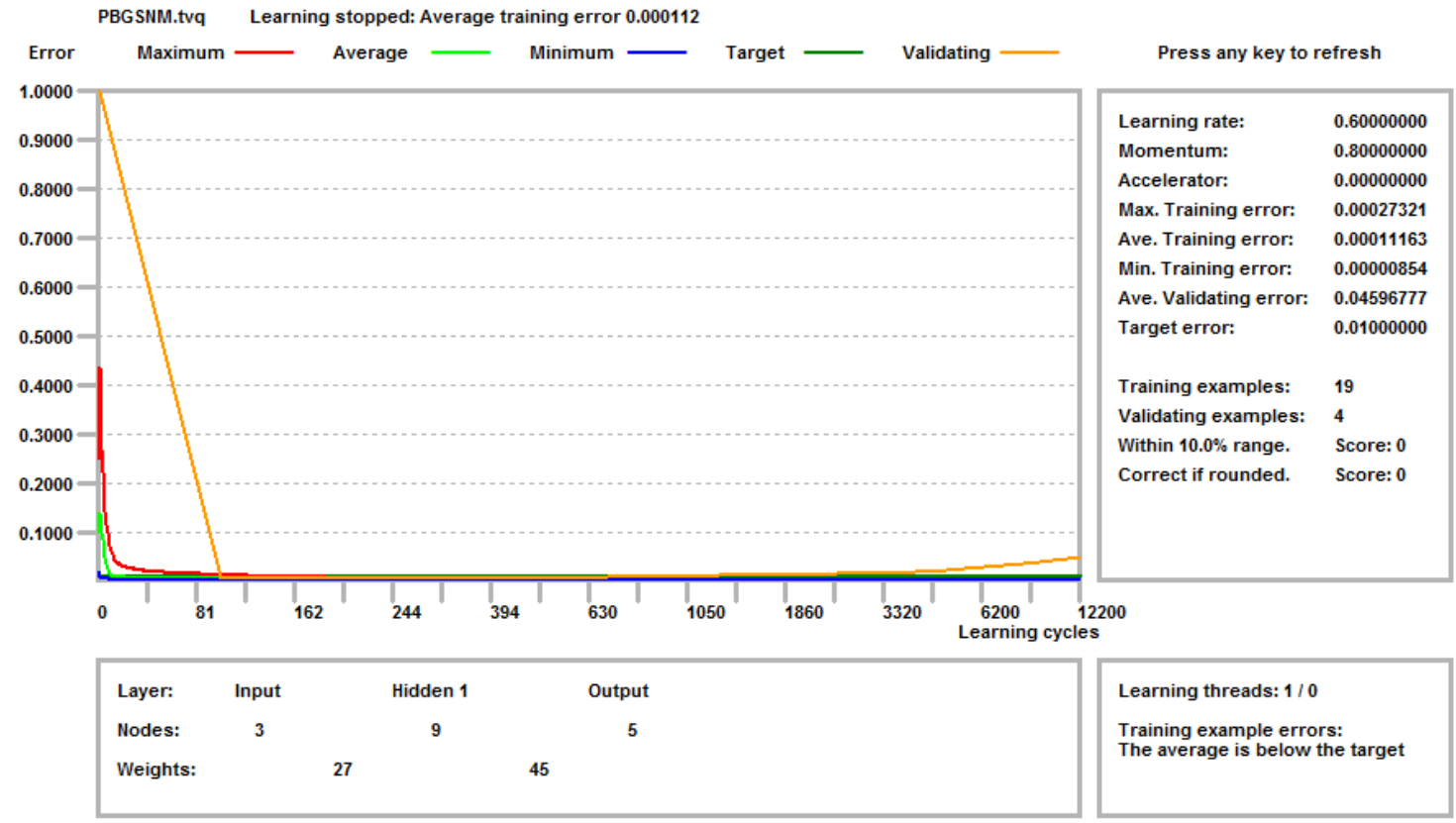

Figure 15. Training progress graph with maximum, average and minimum training error.

Table 4 (a). Experimental data and predicted data of responses.

\begin{tabular}{|c|c|c|c|c|c|c|c|c|}
\hline \multirow{2}{*}{$\begin{array}{l}\text { Exp. } \\
\text { No. }\end{array}$} & \multicolumn{3}{|c|}{$\mathrm{Y}(\mu \mathrm{m})$} & \multirow{2}{*}{$\begin{array}{c}\text { ANN error } \\
(\%)\end{array}$} & \multicolumn{3}{|c|}{$F_{C}(N)$} & \multirow{2}{*}{ ANN error $(\%)$} \\
\hline & Exp. & Sim. & ANN & & Exp. & Sim. & ANN & \\
\hline 5 & 41.0 & 35.7 & 41.2 & 0.49 & 841 & 825 & 802 & 4.86 \\
\hline 10 & 56.2 & 54.5 & 45.6 & 18.86 & 698 & 660 & 714.0 & 2.24 \\
\hline 18 & 78.5 & 79.0 & 89.2 & 13.63 & 1109 & 1019 & 1156 & 4.07 \\
\hline \multirow[t]{2}{*}{25} & 106.2 & 105.0 & 105.3 & 0.85 & 1045 & 1023 & 1070 & 2.34 \\
\hline & \multicolumn{3}{|c|}{ Avg. error } & 8.45 & & \multicolumn{2}{|c|}{ Avg. error } & 3.37 \\
\hline
\end{tabular}

Table 4 (b). Experimental data and predicted data of responses.

\begin{tabular}{lccccccccccc}
\hline $\begin{array}{l}\text { Exp. } \\
\text { No. }\end{array}$ & \multicolumn{3}{c}{ Exp. } & Sim. & ANN $(\mathrm{N})$ & $\begin{array}{c}\text { ANN } \\
\text { error } \\
(\%)\end{array}$ & \multicolumn{3}{c}{$\mathrm{V}_{\mathrm{B}}(\mathrm{mm})$} & \multicolumn{3}{c}{$\begin{array}{c}\text { ANN } \\
\text { error }\end{array}$} & $\begin{array}{c}\text { Ra }(\mu \mathrm{m}) \\
\text { Sim. }\end{array}$ & ANN & $\begin{array}{c}\text { ANN } \\
(\%)\end{array}$ & Exp. & ANN & $\begin{array}{c}\text { error } \\
(\%)\end{array}$ \\
\hline 5 & 283 & 287 & 283.9 & 0.32 & 0.083 & 0.095 & 0.073 & 12.05 & 2.414 & 2.213 & 8.32 \\
10 & 258 & 234 & 255.6 & 0.94 & 0.118 & 0.115 & 0.113 & 4.24 & 2.015 & 2.004 & 0.54 \\
18 & 389 & 376 & 375.3 & 3.65 & 0.165 & 0.195 & 0.197 & 14.39 & 3.562 & 3.645 & 2.33 \\
25 & 341 & 323 & 358.2 & 4.80 & 0.281 & 0.274 & 0.279 & 0.71 & 3.523 & 3.111 & 11.69 \\
\hline \multicolumn{4}{c}{ Avg. error } & 2.42 & \multicolumn{4}{c}{ Avg. error } & 7.85 & Avg. error & 7.85 \\
\hline
\end{tabular}




\section{CONCLUSION}

In the present study, numerical simulation was carried out using DEFORM 3D to validate experimental results of machining characteristics such as surface roughness, cutting force, thrust force, tool wear and tool vibration in the boring of Ti-6Al-4V alloy. Effect of process parameters on the machining characteristics was studied. ANN model was also developed using the experimental data to predict the machining characteristics. Interaction effect of process parameters was discussed. The following conclusion may be drawn from the work:

i. The relative error between experimental results and the simulated results of machining characteristics was found to be very less. The numerical simulation models help to study the machining process and save time and cost.

ii. At high feed rates, more energy is required for plastic deformation of metal consequently there is a raise in temperature and friction at a cutting zone that results in tool wear. Therefore, the cutting force is also increased.

iii. During the machining, the energy of plastics deformation is converted in frictional heat at tool-chip interface and increases as the depth of cut and feed rate increase. That results in tool vibration and wear.

iv. It can be concluded that at low feed rates and depth of cuts, the tool vibration, cutting forces and tool wear were found to be less. Surface roughness was also found to be less at a low level of spindle speed, depth of cut and feed rates.

v. Experimental results, FEM simulated results and ANN predicted results were compared and obtained a good agreement among them.

\section{ACKNOWLEDGEMENT}

This work was funded by Science and Engineering Research Board, Department of Science and Technology, Government of India. Grant No.: SERB/F/1761/2015-16.

\section{REFERENCES}

[1] Lui EW, Palanisamy S, Dargusch MS, Xia K. Effects of chip conditions on the solid-state recycling of Ti-6Al-4V machining chips. Journal of Materials Processing Technology, 2016; 238: 297-304.

[2] Karkalos NE, Galanis NI, Markopoulos AP. Surface roughness prediction for the milling of Ti-6Al-4V ELI alloy with the use of statistical and soft computing techniques. Measurement, 2016; 90: 25-35.

[3] Wu H, Guo L. Machinability of titanium alloy TC21 under orthogonal turning process. Journal of Materials and Manufacturing Process, 2014; 29 (11-12) :1441-1445.

[4] Venkatarao K, Murthy PBGSN. Modeling and optimization of tool vibration and surface roughness in boring of steel using RSM, ANN and SVM. Journal of Intelligent Manufacturing, 2018; 29: 1533-1543.

[5] Inman DJ. Engineering Vibration. 2nd ed. Prentice-Hall; 2001.

[6] Prasad BS. Sarkar MMM, Satish Ben B. Development of a system for monitoring tool condition using acousto-optic emission signal in face turning - an experimental approach. International Journal of Advanced Manufacturing Technology, 2010; 51: 57-67. 
[7] David A, Stephenson, John SA. Metal cutting theory and practice. 1st ed. Taylor and Francis; 2006.

[8] Miguélez MH, Rubio L, Loya JA, Fernández-Sáez J. Improvement of chatter stability in boring operations with passive vibration absorbers. International Journal of Mechanical Sciences, 2010; 52(10): 1376-1384.

[9] Wang H, To S, Chan CY. Investigation on the influence of tool-tip vibration on surface roughness and its representative measurement in ultra-precision diamond turning. International Journal of Machine Tools and Manufacture, 2013; 69: 2029.

[10] Théo D, Guillaume F, Jean PC. Generalised cutting force model including contact radius effect for turning operations on Ti6Al4V titanium alloy. The International Journal of Advanced Manufacturing Technology, 2016; 86 (9): 3297-3313.

[11] Mehmet A, Mehmet U, Abdulkadir C, Mustafa K, Barkın A. Methodology for cutting force prediction in side milling. Materials and Manufacturing Process, 2014; 29(11-12): 1429-1435.

[12] Hamed H, Mohammad H, Sadeghi A, Hamed R, Amir R. Experimental study of cutting force, microhardness, surface roughness, and burr size on micromilling of Ti6Al4V in minimum quantity lubrication. Materials and Manufacturing Process, 2016; 31 (13): 1654-1662.

[13] Rajiv KY, Kumar A, Siba SM. A simulation approach for estimating flank wear and material removal rate in turning of Inconel 718. Simulation Modelling Practice and Theory, 2015; 52: 1-14.

[14] Ducobu F, Rivière-Lorphèvre E, Filippi E. Numerical contribution to the comprehension of saw-toothed $\mathrm{Ti}-6 \mathrm{Al}-4 \mathrm{~V}$ chip formation in orthogonal cutting. International Journal of Mechanical Science, 2014; 81: 77-87.

[15] Filice L, Umbrello D, Beccari S, Micari F. On the FE codes capability for tool temperature calculation in machining processes. Journal of Material Processing Technology, 2006; 174 (1): 286-292.

[16] Arulkirubakaran D, Senthilkumar V, Vijay K. Effect of micro-textured tools on machining of Ti-6Al-4V alloy: An experimental and numerical approach. International Journal of Refractory Metals and Hard Materials, 2016; 54: 165177.

[17] Mohammad L, Jahanbakhsh M, Akhavan Farid A. Wear estimation of ceramic and coated carbide tools in turning of Inconel625: 3D FE analysis. Tribology International, 2016; 99: 107-116.

[18] Mozammel M, Nikhil Ranjan. D. Prediction of surface roughness in hard turning under high pressure coolant using Artificial Neural Network. Measurement, 2016; 92: 464-474.

[19] Venkatarao K, Murthy BSN, Mohanrao N. Prediction of cutting tool wear, surface roughness and vibration of work piece in boring of AISI 316 steel with Artificial Neural Network. Measurement, 2014; 51: 63-70.

[20] Sharma VS, Dhiman R Sharma S. Estimation of cutting forces and surface roughness for hard turning using neural networks. Journal of Intelligent Manufacturing, 2008; 19: 473-483.

[21] Venkata SD, Vamsi KP, Venu GA, Prithvi RCL Parameter Optimization in Vibration Assisted Turning of $\mathrm{Ti}$ 6Al 4V Alloy using ANOVA and Grey Relational Analysis. International Journal of Automotive and mechanical Engineering, 2018; 15 (3): 5400-5420. 
[22] Lotfi M, Farid A, Soleimanimehr H. The effect of chip breaker geometry on chip shape, bending moment, and cutting force: FE analysis and experimental study. International Journal of Advanced Manufacturing Technology, 2015; 78 (5-8): 917-25.

[23] Xie LJ, Schmidt J, Schmidt C, Biesinger F. 2D FEM estimate of tool wear in turning operation. Wea, 2005; 258(10): 1479-90.

[24] Venkatarao K, Anoopkumar T, Vidhu KP, Murthy PBGSN, Narayanarao N, Balaji M. An Artificial Neural Network approach to investigate Surface roughness and Vibration of work piece in boring of AISI1040 steels. International journal of Advanced Manufacturing Technology, 2016; 83:919-927.

[25] Wyen CF, Wegener $\mathrm{K}$ Influence of cutting edge radius on cutting forces in machining titanium. CIRP Annals - Manufacturing Technology, 2010; 59: 9396.

[26] Amir M, Hans G, Ibrahim S, Lars N. An FEM-based approach for tool wear estimation in machining. Wear, 2016; 368-369: 10-24.

[27] Muthu E. Senthamarai K, Jayabal S. Finite element simulation in machining of Inconel 718 nickel based super alloy. International Journal of Advanced Engineering Applications, 2012; 1(3): 22-7.

[28] Sampaul P, Varadarajan AS, Robinson Gnanadurai R. Study on the influence of fluid application parameters on tool vibration and cutting performance during turning of hardened steel. Engineering Science and Technology, an International Journal, 2016; 19: 241-253.

[29] Huang P, Lee WB. Cutting force prediction for ultra-precision diamond turning by considering the effect of tool edge radius. International Journal of Machine Tools and Manufacture, 2016; 109: 1-7. 